\title{
USING DESIGN SCIENCE RESEARCH AND ACTION RESEARCH TO BRIDGE THE GAP BETWEEN THEORY AND PRACTICE IN LEAN CONSTRUCTION RESEARCH
}

\author{
Sheriz Khan ${ }^{1}$ and Patricia Tzortzopoulos ${ }^{2}$
}

\begin{abstract}
The descriptive approaches, like case study, interview, survey, observation and document analysis, widely used by the lean construction community to investigate managerial problems in the construction industry, typically provide explanations of problems and not solutions to them, leaving a gap between theory and practice. Two prescriptive approaches-design science research and action research-are therefore recommended. Design science research and action research offer alternative approaches for studying, understanding and solving practical problems and testing innovative solutions in design and construction management, for bridging the gap between theory and practice and for making academic research more relevant to practice.They can be used to develop and/or test solutions to managerial problems in the construction industry and generate new knowledge and/or theory. The purpose of this paper is to describe design science research and action research and discuss three cases of lean construction research in which these approaches were used effectively.
\end{abstract}

\section{KEYWORDS}

Design Science Research (DSR), Action Research (AR), Lean Construction (LC), the Last Planner System (LPS), Benefit Realization.

\section{INTRODUCTION}

The descriptive research approaches that have traditionally been used to investigate managerial problems in the construction industry have typically placed investigators in the position of observers, rather than solvers of problems and agents of change, thus producing results that are of marginal value to practice (Holmström et al., 2009).

$1 \mathrm{PhD}$ (Architecture), University of Huddersfield, United Kingdom, Telephone: +1 (321) 674-0309, sherizkhan@yahoo.com

2 Professorof Integrated Design/Associate Dean of Research and Enterprise, School of Art, Design and Architecture, University of Huddersfield, United Kingdom. Fax: (+44) 01484 472440, p.tzortzopoulos@hud.ac.uk 
Prescriptive research approaches, like DSR and AR, "could be more beneficial for the construction industry and may lead to better management practices, more effective field procedures, and improved levels of productivity." (Azhar et al., 2010, p. 87). These two approaches make it possible for practitioners themselves to become involved with researchers in studying their work (Stenhouse, 1975) and becoming co-researchers, coproblem-solvers and co-agents of change. However, DSR and A Rare rarely considered when investigating and solving managerial problems in the construction industry, including lean construction research.

Daniel et al. (2015) found that the vast majority of studies with defined methods published by the International Group for Lean Construction (IGLC) on the implementation of LPS in building projects used descriptive research methods like case study, interview, survey, observation and document analysis (see Figure 1). According to Daniel et al. (2015, p. 159):

...this should be a point of concern to the IGLC research community that is seeking to build lean construction on sound theories and principles for better practice. Sound theories can only be developed from sound methods and methodologies...

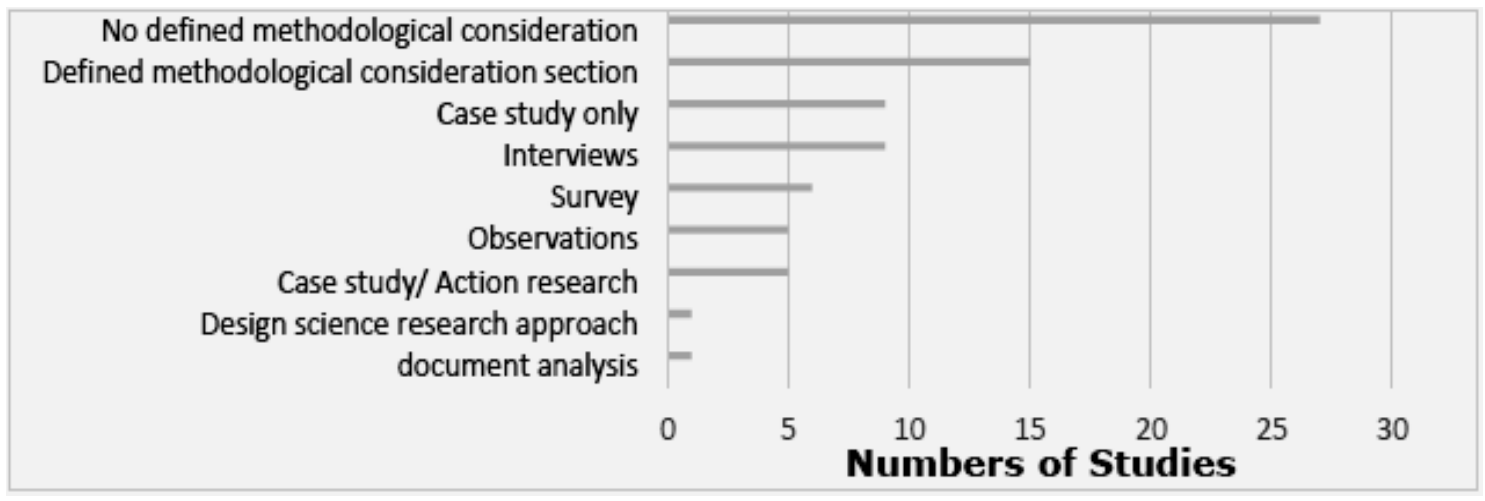

Figure 1: Research methods used in LPS implementation reported in fifty-seven IGLC conference papers (Source: Daniel et al., 2015, p. 159)

Below, the authors briefly describe DSR and AR, argue that LPS is a good example of an output of what may be considered design science research and demonstrate how action research was used in two PhD investigations to implement LPS in two building projects and evaluate its effectiveness in increasing production planning reliability.

\section{DESIGN SCIENCE RESEARCH}

DSR has its origin in engineering and the sciences of the artificial (Simon 1996). According to Lukka (2003), DSR "focuses on developing and evaluating innovative artifacts, intended to solve real-world problems and to make a contribution to the theory of the discipline in which it is applied." March and Smith (1995) proposed four artifacts that can be developed and evaluated in DSR: constructs, models, methods and instantiations (see Table 1). 
Table 1: Artifacts of DSR as defined by March and Smith, 1995

\begin{tabular}{|l|l|}
\hline \multicolumn{1}{|c|}{ Artifact/Outputs } & \multicolumn{1}{c|}{ Definition } \\
\hline Constructs & $\begin{array}{l}\text { Concepts forming the vocabulary of a domain. They constitute a } \\
\text { conceptualization used to describe problems within the domain and } \\
\text { to specify their solutions. }\end{array}$ \\
\hline Model & $\begin{array}{l}\text { A set of propositions or statements expressing relationships among } \\
\text { constructs. In design activities models represent situations as problem } \\
\text { and solution statements. }\end{array}$ \\
\hline Method & $\begin{array}{l}\text { A set of steps (an algorithm or guideline) used toper form a task. } \\
\text { Methods are based on a set of underlying constructs (language) and a } \\
\text { representation (model) of the solution space. }\end{array}$ \\
\hline Instantiation & $\begin{array}{l}\text { The realization of an artifact in its environment, that is, the } \\
\text { implementation(s) of constructs, models and methods, demonstrating } \\
\text { the feasibility of the conceptual elements that the solution contains. }\end{array}$ \\
\hline
\end{tabular}

\section{ACTION RESEARCH}

$\mathrm{AR}$ is a strategy for implementing and evaluating an existing solution to a practical problem in its organizational context, with the knowledge acquired from the implementation and evaluation used to make recommendations for future implementation of the solution (Iivari and Venable, 2009)and to produce guidelines for best practice (Denscombe, 2010). Lewin (1946) is credited with pioneering AR. According to him, social practices can only be understood and changed by involving and being involved with the practitioners themselves throughout an inquiry. He portrayed AR as a spiral of learning cycles consisting of planning action, taking action, evaluating action and amending the plan based on what was learned.

\section{PARADIGMATIC ASSUMPTIONS OF DSR AND AR}

According to Vaishnaviand Kuechler (2008), DSR makes certain ontological (concerned with the nature of reality, what is real and what is not, what is fundamental and what is derivative) and epistemological (concerned with the nature of knowledge and how we can be sure of what we know) assumptions that set it apart from the positivist and interpretative theoretical perspectives. For example, DSR advocates creative manipulation and control of phenomena through the development and application of solutions while the positivist theoretical perspective is mainly concerned with the pursuit of truth (Vaishnaviand Kuechler, 2008). Based on the foregoing, it may be argued that DSR is more than just a research approach; it is a whole new way of looking and thinking about research (Manson, 2006). The procedures for conducting and the criteria for assessing DSR are therefore different from procedures for conducting and the criteria for assessing natural science research and formal science research. DSR aims to construct new and innovative ways to solve a class or classes of problems, thus creating new 
reality. AR differs from DSR in that it does not necessarily aim to construct new and innovative solutions for a class or classes of problems. Much of AR is conducted to understand existing reality, such as the complex workings of organizational situations and human behavior (Iivari and Venable,2009).

\section{THE LAST PLANNER SYSTEM}

Glenn Ballard and Greg Howell developed LPS as an innovative pull production control system that is needed to supplement the traditional push project management system in order to increase production planning reliability in design and construction projects(Ballard, 2000), using an approach similar to DSR (see Table 2). The output of their work may be regarded a method (or system), as defined in Table 1.

Table 2: Similarity between the approach adopted by Ballard and Howell and the DSR steps proposed by Kasanen et al. (1993)

\begin{tabular}{|c|l|l|}
\hline Step & \multicolumn{1}{|c|}{$\begin{array}{c}\text { Kasanen et al. } \\
\text { (1993) }\end{array}$} & \multicolumn{1}{c|}{ Approach adopted by Ballard and Howell } \\
\hline 1 & $\begin{array}{l}\text { Find a problem with } \\
\text { practical relevance } \\
\text { and that also has } \\
\text { research potential }\end{array}$ & $\begin{array}{l}\text { Ballard and Howell found a problem with practical relevance and } \\
\text { that also had research potential: low production planning reliability } \\
\text { associated with traditional the project management systems. }\end{array}$ \\
\hline 2 & $\begin{array}{l}\text { Obtain an } \\
\text { understanding of the } \\
\text { topic }\end{array}$ & $\begin{array}{l}\text { Ballard and Howell obtained an understanding of the topic. } \\
\text { Through literature review, they gained an understanding of } \\
\text { production and production control, traditional project } \\
\text { management, previous applications of production control concepts } \\
\text { to the AEC industry, principles for a production control system } \\
\text { proposed by Koskela (1999) and criteria for a design production }\end{array}$ \\
\hline 3 & $\begin{array}{l}\text { Innovate, namely, } \\
\text { construct a solution }\end{array}$ & $\begin{array}{l}\text { Ballardand Howell innovated, i.e., they constructed, a solution. } \\
\text { They developed LPS as a solution to low planning reliability } \\
\text { associated with the push project management system traditionally } \\
\text { used in design and construction. They added "a production control } \\
\text { component to the traditional project management system" } \\
\text { (Ballard, 2000, p. 3-14). }\end{array}$ \\
\hline 4 & $\begin{array}{l}\text { Demonstrate that } \\
\text { the solution works }\end{array}$ & $\begin{array}{l}\text { To demonstrate that the solution works, Ballard (2000) analyzed } \\
\text { data collected during the implementation of LPS or elements of it } \\
\text { in five design as well as construction projects. The methods he } \\
\text { used to collect data included direct observations, interviews, } \\
\text { questionnaires and document reviews. He relied on PPCs (Percent } \\
\text { Plan Complete), RNCs (Reason for Non-Completion of tasks) and } \\
\text { "team member assessments" (Ballard, 2000, p. 4-10) to measure } \\
\text { the performance of his system. }\end{array}$ \\
\hline
\end{tabular}




\begin{tabular}{|l|l|l|}
\hline 5 & $\begin{array}{l}\text { Present its } \\
\text { connection to theory } \\
\text { and its contribution } \\
\text { to research }\end{array}$ & $\begin{array}{l}\text { Ballard (2000) presented the connection of LPS to theories on the } \\
\text { application of lean production principles to construction by } \\
\text { Koskela (1992) and on production control in construction by } \\
\text { Melles \& Wamelink (1993). He presented the contribution of LPS } \\
\text { to research by demonstrating that LPS combines practice with } \\
\text { theory through research. }\end{array}$ \\
\hline 6 & $\begin{array}{l}\text { Assess the scope of } \\
\text { application of the } \\
\text { solution }\end{array}$ & $\begin{array}{l}\text { Ballard (2000) assessed the scope of application of the solution. } \\
\text { He found out that LPS improved workflow in construction (prime } \\
\text { as well as subcontracted) projects and in design projects. }\end{array}$ \\
\hline
\end{tabular}

\section{USING AR TO IMPLEMENT AND EVALUATE THE EFFECTIVENESS OFLPS IN CONSTRUCTION PROJECTS}

The construction industry in Saudi Arabia suffers from acute managerial problems, including poor planning, low productivity, mistakes and rework (MOP, 1997; Al-Saqer, 2001), which cause costly delays. Traditional construction planning practices lack a mechanism to manage workflow (Ballard, 2000; Howell, 2003). Studies have shown that LPS reduces workflow variability during the construction stage of building projects by increasing planning reliability through greater collaboration in the planning of construction tasks and better coordination of work between the building trades.

LPS has four planning levels: Master Planning, Phase Planning, Look-ahead Planning andWeekly Work Planning(WWP). For his PhD research, AlSehaimi (2011) adopted an AR approach to facilitate the implementation of LPS Phase Planning, Look-ahead Planning and WWP in two large construction projects in Saudi Arabia over an eighteenweek period and evaluate its effectiveness in improving the construction planning and control process and reducing delay. Figure 2 summarizes the procedure AlSehaimi (2011) followed. 


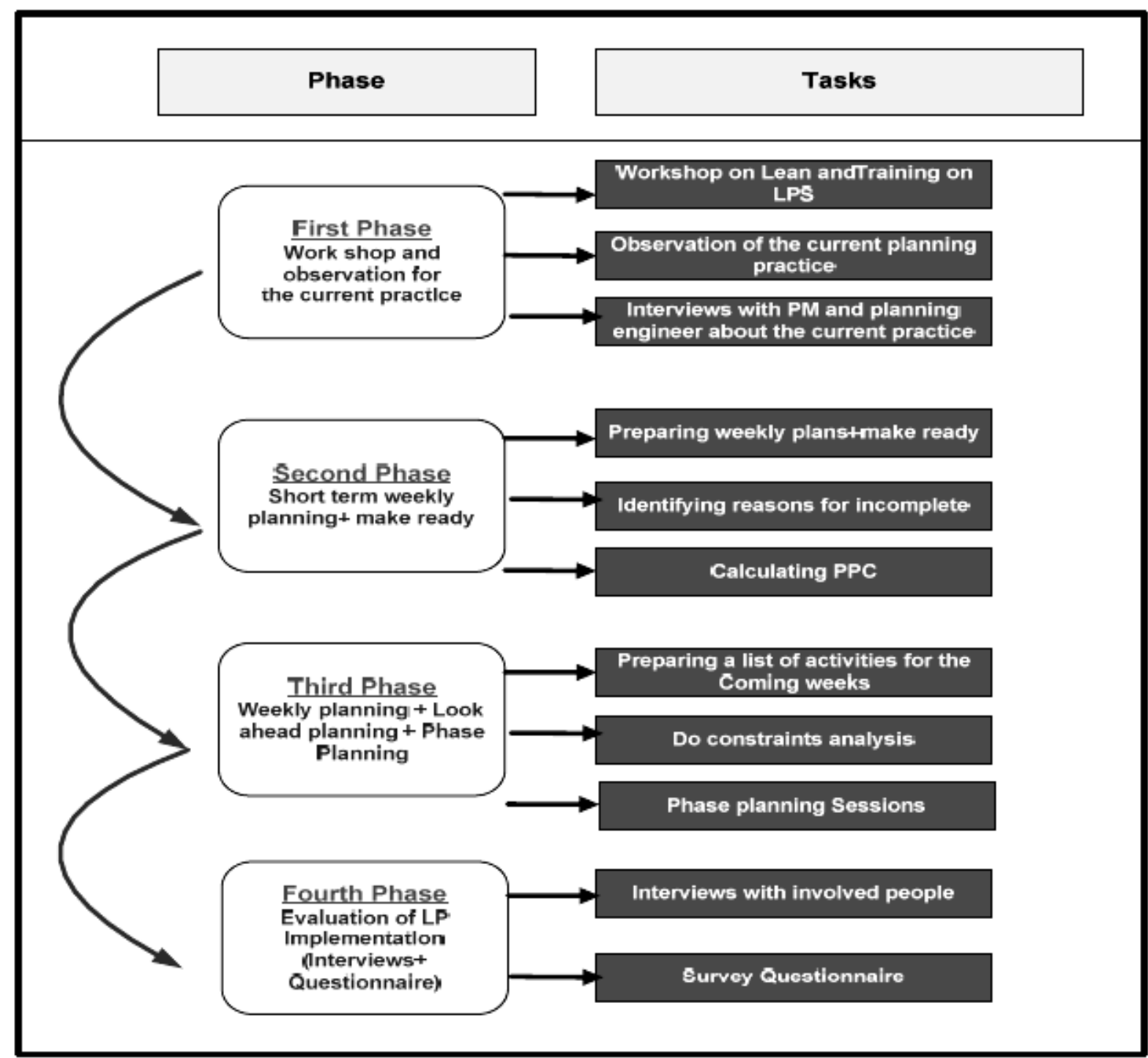

Figure 2: The LPS implementation procedure followed by AlSehaimi (2011)

AlSehaimi (2011) referred to one of the construction projects as B12 and the other as B16. He collected data for his research through interviews, observation, document review and a survey questionnaire. He synthesized, analyzed and discussed the data he collected, and he compared his findings with those of earlier studies on LPS in other countries. He reported PPC in Project B12 rising from 69\% in Week 1 to as high as 100\% in Week 6 (see Figure 3) and PPC in Project B16 rising from 42\% in Week 2 to as high as $84 \%$ in the Week 10 and Week 13(see Figure 4), although "the project was always struggling to keep pace with the weekly and look-ahead plans, because the available workforce was insufficient to meet needs" (AlSehaimi, 2011, p. 226). The responses to his survey questionnaire revealed that LPS provided many advantages over traditional methods of project management to both the contractor and the owner. Based on the lessons learned and knowledge gained in his research, AlSehaimi (2011) made four recommendations for the implementation of the LPS in the Saudi Construction industry. 


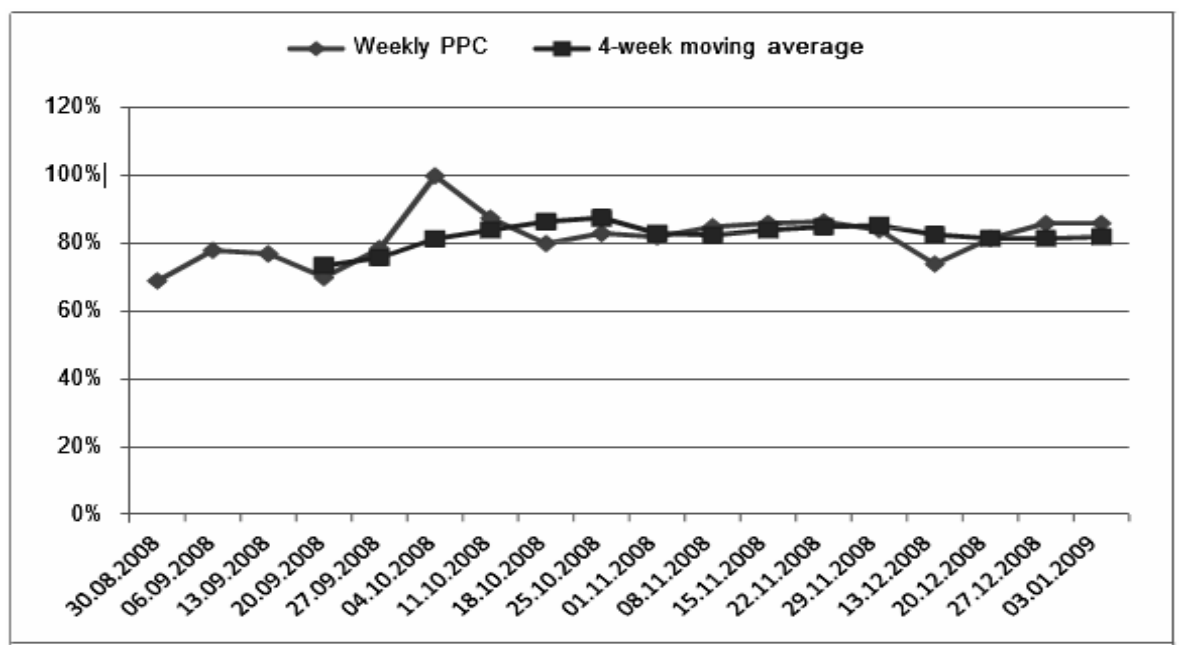

Figure 3: Trend in PPC values for Project B12 (AlSehaimi, 2011: 162)

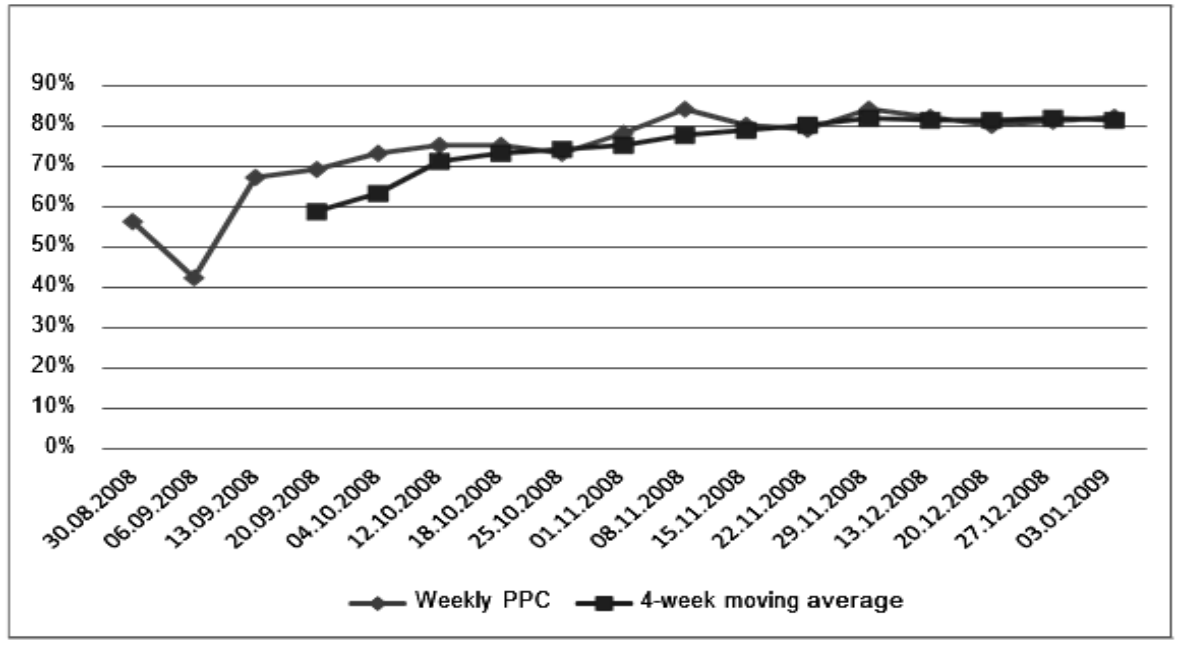

Figure 4: Trend in PPC values for Project B16 (AlSehaimi, 2011: 227)

\section{USING AR TO IMPLEMENT AND EVALUATE THE EFFECTIVENESS OFLPS IN DESIGN PROJECTS}

At the WWP level of LPS, the right sequence of work and the right amount of work that can be done are selected (Ballard \& Howell, 1994). It is therefore believed that LPSWWP can be used as a production control mechanism toreduce workflow variability during the design stage of building projects by increasingplanning reliability through greater collaboration in the planning of tasks and better coordination of work between the design disciplines. For his PhD research, Khan (2016)adopted an AR approach to facilitate the implementation of LPS WWP and short-term make-ready planning during the final twelve weeks of the sixteen-week design development phase of a seven-story hotel and a six-story apartment at two different AE firms in Florida and evaluate their effectiveness in increasing planning reliability and reducing workflow variability. As shown in Figure 
5, his research took the form of a flexible spiral process which allowed action (change, improvement) and research (understanding, knowledge) to be achieved at the same time (Dick, 2002).

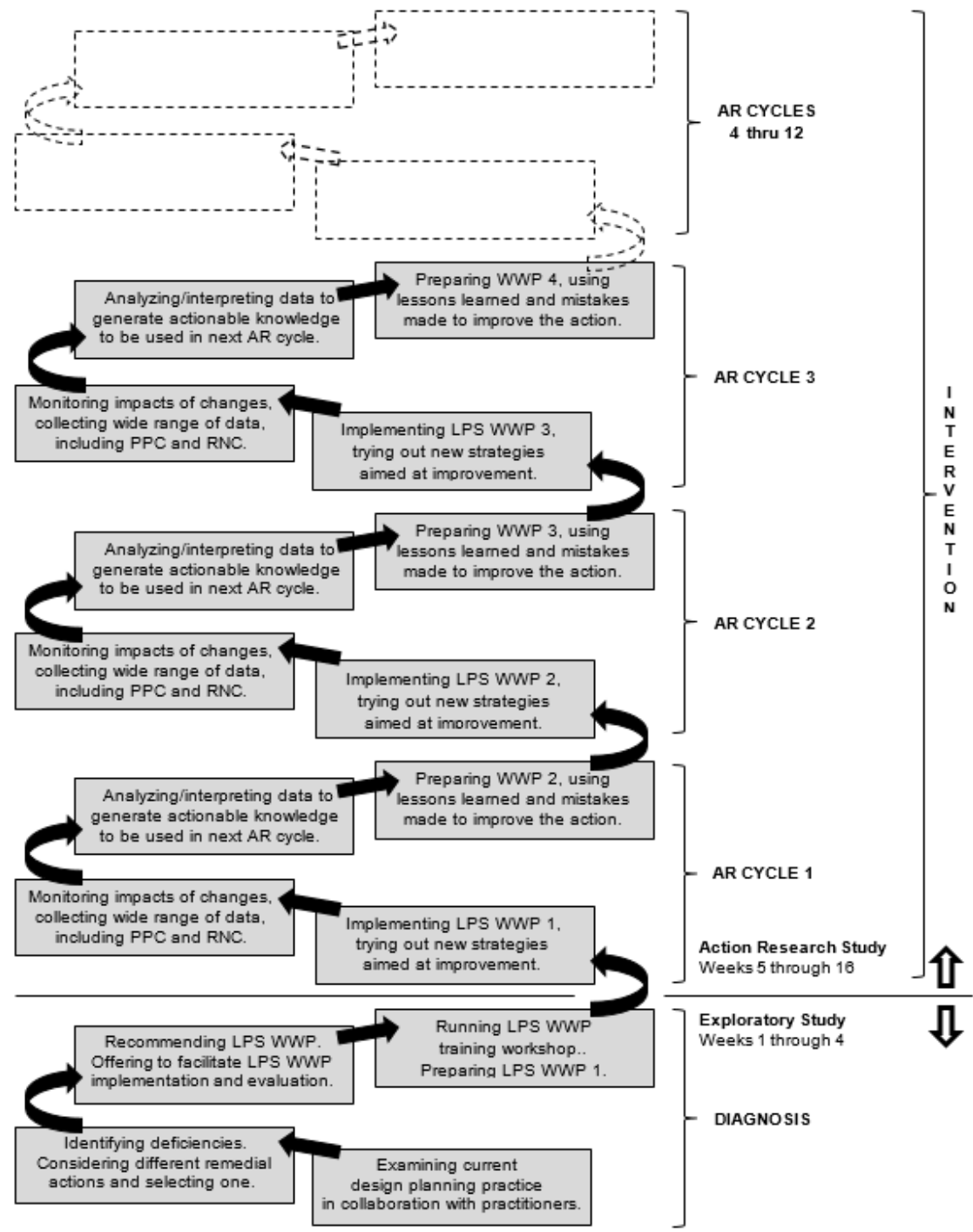

Figure 5: The action research spiral (Khan, 2016)

PPCs were collected at the end of each of the first four weeks of the design development phase to measure planning reliability during this period of traditional weekly task planning (WTP). These PPCs were later compared with LPS WWP PPCs to determine whether there had been any increase or decrease in planning reliability and thus any decrease or increase in workflow variability. Figure 6 show a steady rise in PPCs in both design projects after the fourth week, suggesting that LPS WWP was effective in increasing planning reliability in both design projects and thus improving design workflow. 


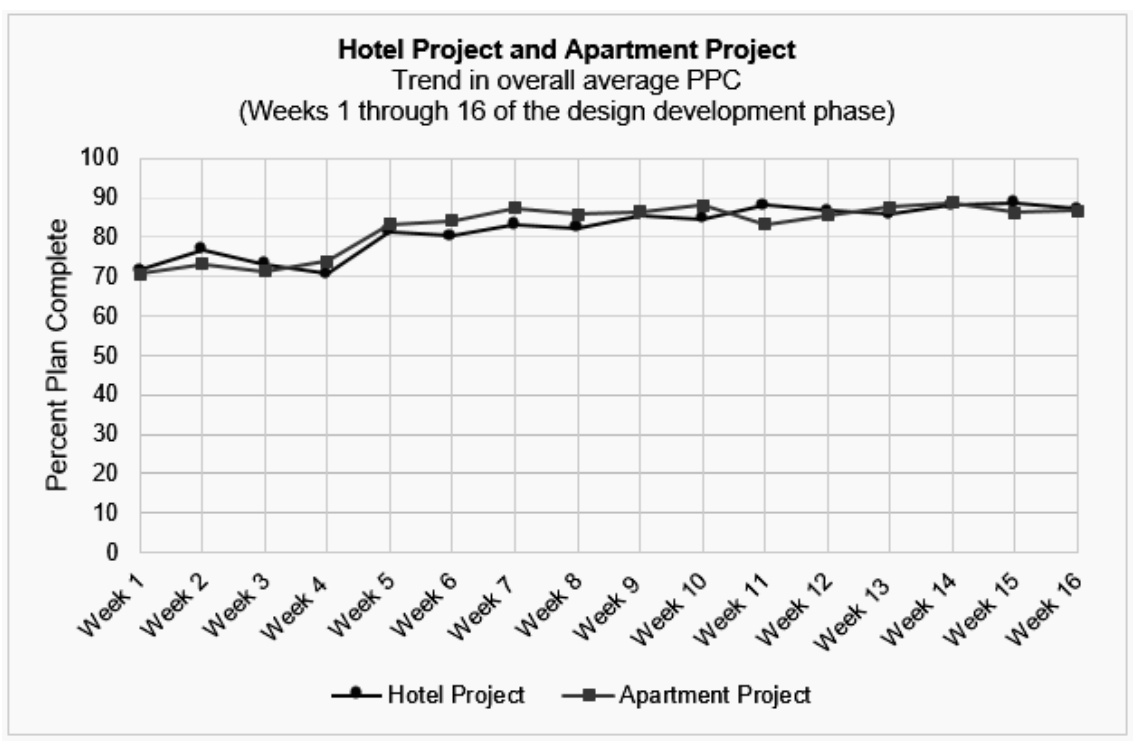

Figure 6: Both design projects—changes in overall average LPS WWP PPC

PPC measurements taken before and after the implementation of LPS WWP increased by an average of $12.1 \%$ in the hotel project and by an average of $13.9 \%$ in the apartment project after LPS WWP was implemented, representing an upward trend in PPC and continual improvement in design workflow (see Figure 7).

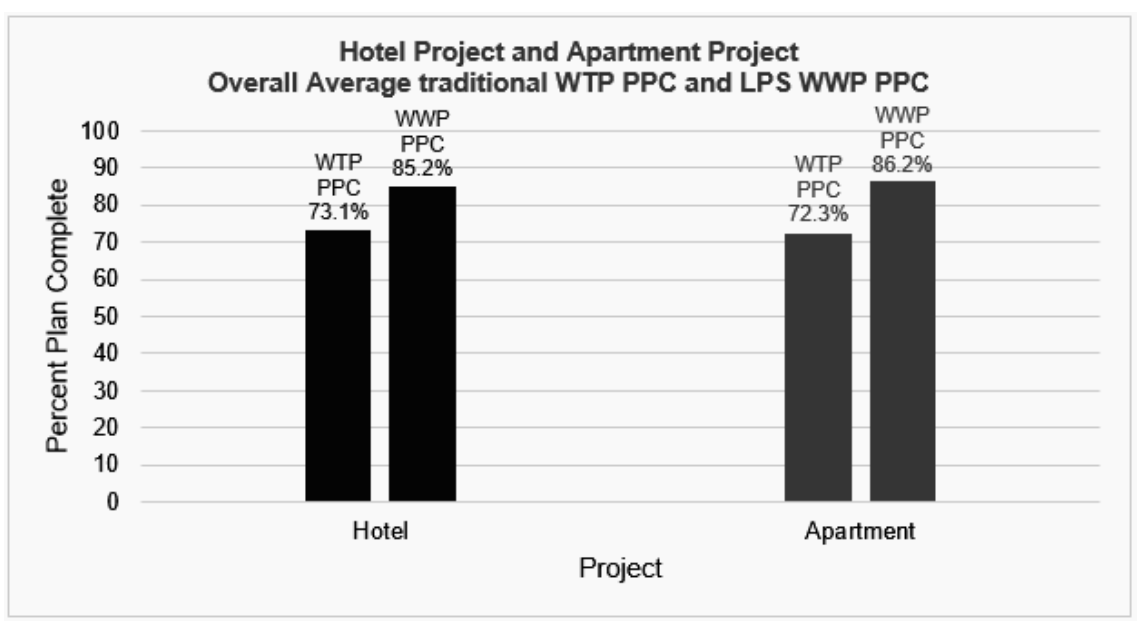

Figure 7: Both design projects - traditional WTP PPC and LPS WWP PPCcompared 
Using the knowledge gained and the lessons learned during the implementation and evaluation of the LPS WWP and short-term make-ready planning in the two building design projects, Khan (2016) made twelve recommendations for future implementation of LPS WWP and short-term make-ready planning during the design development phase of similar design projects.

\section{CONCLUSION}

Lean construction is the adaptation of lean manufacturing principles to building design and construction processes. Adaptation of lean principles from the manufacturing industry requires the development of valid and reliable knowledge that can be used to create lean solutions to practical problems in the construction industry. DSR can be used to develop such knowledge. Lean solutions to practical problems in the construction industry can be implemented and evaluated in their organizational context using AR. AR is a research approach based on a collaborative solution-testing relationship between researcher and practitioners that can be used to implement and evaluate innovative solutions to practical problems in their organizational context, with the knowledge acquired from the implementation and evaluation used to make recommendations for future implementation of the solution (Iivari and Venable, 2009) and to produce guidelines for best practice (Denscombe, 2010).

The authors strongly recommend DSR and AR as the best research approaches for developing, implementing and evaluating innovative lean solutions.

\section{REFERENCES}

Al-Saqer, K. (2001). An Investigation into the Development Processes and Project Management Practices of Government Construction Projects in Saudi Arabia. PhD Thesis, University of Birmingham, UK.

AlSehaimi, A. (2011). Improving Construction Planning Practice in Saudi Arabia by Means of Lean Construction Principles and Techniques. PhD Thesis, School of the Built Environment, University of Salford, UK.

Azhar, S. Ahmad, I.,and Sein, M. (2010). Action research as a proactive research method for construction engineering and management.Journal of Construction Engineering and Management (C) ASCE / January 2010.

Ballard, G. (2000). The Last Planner System of Production Control. PhD Thesis, University of Birmingham, UK.

Ballard, G., \& Howell, G. (1994). Implementing lean construction: Stabilizing the work flow. In Proceedings of the 2nd Annual Conference of the International Group for Lean Construction. Santiago, Chile. September 28-30.

Daniel, E., Pasquire, C., and Dickens, G. (2015). Exploring the implementation of the Last Planner System through IGLC community: Twenty one years of experience. In Proceeding of the $23^{\text {rd }}$ Annual Conference of the International Group for Lean Construction, Perth, Australia, July 29-31. 
Da Rocha, C., Formoso, C., Tzortzopoulos, P., Koskela, L., and Tezel, A. (2013). Design science research in lean construction: Process and outcomes. Proceedings of the $21^{\text {st }}$ Annual Conference of the International Group for Lean Construction, Fortaleza, Brazil.

Denscombe, M. (2010). The good research guide for small-scale social research. (4th ed.). Maidenhead, UK: Open University Press.

Dick, B. (2002). Action Research: Action and Research. Retrieved from http://www.scu.edu.au/schools/gcm/ar/arp/aandr.html.

Holmström, J., Ketokivi, M.,andHameri, A. (2009). Bridging practice and theory: A design science approach. Decision Sciences, 40(1), 65-87.

Howell, G. (2003). The Last Planner System: Workflow management. In Construction Innovation Forum, Bloomfield Hills, MI.

Iivari, J.,and Venable, J. (2009). Action research and design science research - seemingly similar but decisively dissimilar. Special Issue of MIS Quarterly, 17th European Conference on Information Systems, Verona, Italy.

Kasanen, E., Kari, L., andSiitonen, A. (1993). The constructive approach in management accounting research. Journal of Management Accounting Research, 5, 243-264.

Khan, S. (2016). Using the Last Planner System and lean principles to improve workflow in BIM-based building design projects. PhD Thesis, School of Art, Design and Architecture, University of Huddersfield, UK, in collaboration with the School of the Built Environment, University of Salford, UK.

Lukka, K. (2003). The constructive research approach. In: Case Study Research in Logistics. L. Ojala and O. Hilmola, (Eds). Publications of the Turku School of Economics and Business Administration, Series B1: 2003, pp.83-101.

Manson, N. (2006). Is operations research really research? Orion, 22(2), 155-180.

March S.,and Smith, G. (1995). Design and natural science research on information technology. Decision Support Systems, 15 (4), 251-266.

MOP. (1997). Kingdom of Saudi Arabia: History, Civilization, Development. Ministry of Planning, Saudi Arabia.

Stenhouse, L. (1975). An introduction to curriculum research and development. London, UK: Heinemann.

Vaishnavi, V.,andKuechler Jr., W. (2008). Design Science Research Methods and Patterns: Innovating Information and Communication Technology. Boca Raton FL: Auerbach Publications, CTC Press, Taylor \& Francis Group. 